\title{
Violências Contemporâneas e Infância: humanização como resposta.
}

\author{
Valdir Cimino \\ Mestre em Ciências da Saúde pela \\ Faculdade de Ciências Médicas \\ da Santa Casa de São Paulo \\ Professor na Faculdade de Comunicação \\ da Fundação Armando Alvares Penteado
}

\section{Resumo}

O mundo contemporâneo, dinâmico, veloz e exageradamente competitivo, nos faz refletir sobre a quantidade de informação irrelevante é transmitida para as crianças. Passar a infância postada em frente a meios de comunicação como a televisão ou internet, esta só. A falta de tempo dos adultos, paciência e tolerância desumanizam as relações e a construção de valores. E é no âmbito da saúde que refletimos o quanto as crianças podem ensinar pais e cuidadores, profissionais da saúde e voluntários a despertarem os sentimentos de bem querer, de cuidar, tendo a certeza de respeitar o tempo do outro.

Palavras chave: Humanização da Saúde; infância; violências.

Cimino, Valdir. "Violências Contemporâneas e Infância: humanização como resposta", in Anais do 20. Congresso Internacional Sabará de Especialidades Pediátricas

\section{Humanização e Políticas Públicas}

A reflexão sobre o título "Violências Contemporâneas e Infância: humanização como resposta” se fará através de três artigos publicados na Revista Marketing produzidos pela Editora Referencia; A saúde está na fila de espera da UTI, Outubro 2011; Eva e Pandora, as culpadas das desgraças do mundo? Março 2012 e Inovar: política social e desenvolvimento na educação e saúde, fevereiro, 2013.

\section{A saúde está na fila de espera da UTI}

A necessidade de promover a humanização da saúde se fez necessária a partir do momento em que o ser humano passou a ser considerado mera estatística de uma fila interminável, uma parte, um número ou simplesmente uma doença. 
Discutir sobre humanização nas relações entre os sujeitos que produzem saúde, ou seja, todos nós, ainda é tema banalizado por muitos gestores e corporações que se utilizam deste apelo para se autopromoverem, esquecendo-se dos fatores continuidade, mudança de cultura, economia na saúde e, por fim, o bem-estar de uma sociedade que está cansada de esperar na fila para conseguir um leito na UTI. É lei multiplicar as boas práticas na saúde, acolher o paciente em sua totalidade, valorizar os profissionais, os gestores e líderes comunicativos. Todo cidadão deveria ler o conteúdo dos dispositivos HumanizaSUS, incluindo os que pagam plano de saúde e, principalmente, os profissionais de jornalismo, comunicação, marketing e relações públicas, que têm o poder de promover e fazer com que a política pública seja compreendida por todos os sujeitos envolvidos.

Com o fortalecimento da tecnologia e a globalização, o século XXI se posicionou como era do conhecimento, da comunicação, da informação. E, coincidência ou não, percebemos que os maiores problemas da humanidade, e para ficarmos mais próximos de nós mesmos, da saúde brasileira, é a comunicação, ou melhor, a falta dela. Vamos traduzir “falta de comunicação" em uma equação simples: eu falo, você não me entende, as coisas não acontecem.

O futuro de nossos profissionais da saúde e da gestão da saúde em si depende, portanto, da educação e da boa comunicação, fundamental para todos, pois, se pacientes possuem desejos, opiniões e culturas diferentes, uma boa comunicação pode ajudar a evitar conflitos e auxiliar na compreensão desses desejos melhorando, assim, a qualidade e o cuidado com a vida. Saber viver é saber se comunicar. Desta forma, a equação está resolvida.

\section{Eva e Pandora, as culpadas das desgraças do mundo?}

Desde 2006 no Instituto de Psiquiatria do Hospital das Clinicas de São Paulo a pesquisa "O brincar como atividade terapêutica nos tratamentos psiquiátricos de crianças e adolescentes", é um trabalho contínuo de grandes descobertas sobre o comportamento humano desenvolvido em parceria com a Associação Viva Deixe Viver, objetiva observar com os pais e acompanhantes o interesse do paciente pelo brincar e contar histórias; verificar os métodos e maneiras utilizadas no brincar das crianças e adolescentes e suas famílias em tratamento psiquiátrico; identificar patologias através do brincar e contar histórias para facilitar processos de interação dos pacientes, equipe multiprofissional e as famílias.

Os resultados preliminares apontaram que do total de 65 casos pesquisados, $70 \%$ dos pacientes são do sexo masculino. As lembranças negativas mais fortes na vida dessas cuidadoras estão ligadas a dores afetivas, causadas pela violência doméstica e problemas financeiros, como: fome, moradia precária, poucas roupas, falta de brinquedos. Mais de um terço da amostra relatam problemas de relacionamento no lar, com pais que bebiam e batiam na mãe e nos filhos, casais que brigavam muito.

”As mães têm que aconselhar muito os filhos, tá mais presente, sempre que tiver em casa conversar mais com o filho, dar mais conselho. Porque hoje eu vejo que lutei muito pouco pelo meu filho. Eu tinha que ter lutado mais. Muito mais. Tinha que ter dado um jeito de ter ficado mais com ele, para dar mais conselho pra ele. (...) Eu fui o pai e mãe deles. Hoje eu vejo que eu não lutei nada pelo Diogo, porque ele morreu 
criança, não deu tempo de eu fazer muita coisa por ele. Hoje vejo que de certa maneira eu ajudei a matar o meu filho, e isso é o que mais me dói”.

O depoimento extraído do livro “As Mulheres do Tráfico”, de MV Bill e Celso Athayde, mostra claramente o sofrimento de uma mãe que também foi pai e chora pelo tempo que não teve em sua vida para poder conversar, aconselhar, educar seu rebento. "São as mulheres que carregam a culpa pelos desastres ocorridos em sua família, mesmo que decorrentes de circunstâncias alheias à sua vontade”.

Desde que o mundo é mundo a mulher tem sofrido o estigma de Pandora e Eva, a primeira criada por Zeus com atributos provenientes de diversos deuses da mitologia grega como a beleza infinita vinda de Vênus, a língua de Mercúrio, a voz macia veio de Apolo e Atena que lhe ofertou um belíssimo vestido que permitia perceber as formas suaves do corpo. Toda esta sensualidade nasceu com o intuito de castigar Prometeu, defensor da humanidade. O presente entregue por Zeus era uma caixa onde foram colocados todos os males da humanidade, como o orgulho, a ambição, a crueldade, a traição, as doenças, as pestes, ou seja, a desgraça humana. Prometeu tinha ciência de que não poderia receber nenhum presente, então Pandora encantou Epimeteu, irmão de Prometeu, que se apaixonou perdidamente e abriu a tal caixa, a partir daí a raça humana perdeu a felicidade de viver no eterno paraíso. Esta mesma desesperança encontramos na história de Eva, que, tentada pela serpente (desejo), come e depois oferece a Adão o fruto da árvore do conhecimento do bem e do mal, proibido por Deus. Ambos são banidos do paraíso e, mais uma vez, a culpa de todos os problemas da humanidade passa a recair sobre a mulher. A história do mundo é exatamente a evolução das crendices e das religiões vivenciadas pelo homem, em ambos os casos a ignorância e o preconceito contra a mulher foram promovidos por divindades masculinas. E em um mundo em profunda transformação vale refletir sobre a visão de (Galeano, Eduardo, 1999)

"Dia a dia nega-se às crianças o direito de ser crianças. Os fatos, que zombam desse direito, ostentam seus ensinamentos na vida cotidiana. O mundo trata os meninos ricos como se fossem dinheiro, para que se acostumem a atuar como o dinheiro atua. O mundo trata os meninos pobres como se fossem lixo, para que se transformem em lixo. E os do meio, os que não são ricos nem pobres, conserva-os atados à mesa do televisor, para que aceitem desde cedo como destino, a vida prisioneira. Muita magia e muita sorte têm as crianças que conseguem ser crianças.

\section{Inovar: política social e desenvolvimento na educação e saúde}

A pobreza educacional e as desigualdades sociais, principalmente as regionais, onde o fluxo de renda mal distribuído infere no crescimento da violência nas ruas, no trabalho, na família, ou seja, no dia a dia do cidadão brasileiro, reafirma a barbárie da descriminação de gênero, raça, idade e, junto com a falta do exercitar e valorizar a vida humana, nos faz acreditar que estamos muito longe da luz no final do túnel. A baixa qualidade dos serviços públicos só vem reafirmar a ignorância do povo que ainda acredita nos discursos de políticos que garantem que 
todo serviço gerado pelo governo é de "graça”; aliás, esta frase foi bem utilizada nas campanhas comunicacionais da última eleição.

A educação é o pilar para todos os problemas de nossa sociedade, o aprendizado contínuo tanto de nossas crianças como dos educadores fará a diferença para as gerações que estão por vir.

A tecnologia da comunicação através da globalização e das redes sociais acredito ser o grande fator de inovação para cobrar de nossos políticos as promessas que o fizeram estar no posto e cargo que estão. Precisamos aprender a cobrar os resultados efetivos na educação, no ambiente e principalmente na saúde.

Reconhecer a escassez de recursos na saúde é o primeiro passo que qualquer politico deveria dar antes de promover em suas campanhas que a saúde é “de graça”.

O sistema de saúde é complexo e a única solução possível é o fomento de políticas públicas fundamentadas na prevenção, diagnóstico, aderência na terapia e reabilitação. Se todo cidadão que produz saúde investisse na prevenção, unindo o paradoxo educação e saúde, seria um alívio no sofrimento, na redução da fila, no acolhimento e principalmente na valorização dos profissionais da saúde.

Mais do que nunca precisamos fazer valer os dispositivos constitucionais da Carta de 1988, um desafio permanente para todos os sujeitos que produzem saúde e educação.

Existe muito avanço, mas ainda não é possível vislumbrar a transparência devido às mazelas sociais e econômicas que destroem o cotidiano de nosso Brasil.

Sem ordem não há progresso, e o progresso sofre um grande embate que envolve orientações ideológicas e teorias metodológicas, ou seja, o que um politico constrói, vem o outro e destrói. A falta de continuidade em projetos de sucesso deixa a desejar e frustram uma nação e aumenta o custo-Brasil, gerando consequências incertas sobre as possibilidades de desenvolvimento social sustentável.

Inovar é olhar para o próprio umbigo e fazer a diferença acompanhando sistematicamente o desenrolar das politicas sociais e seus processos e resultados.

\title{
English Title
}

Contemporary violence and childhood: humanization in response

\begin{abstract}
:
The contemporary world, dynamic, speedy and overly competitive, makes us reflect on the amount of irrelevant information is transmitted to the children. Pass the childhood posted in front of the media like television or the internet, this only. The lack of adult time, patience and tolerance dehumanize relations and the construction of values. And is in the field of health that reflects how much children can teach parents and caregivers, health professionals and volunteers to be human.
\end{abstract}

Keywords: Humanization of health; childhood; violence. 


\section{Referencias}

Athayde, Celso; Bill, Mv . Falcão - Mulheres e o Tráfico, OBJETIVA, 2007.

Cimino, Valdir; A saúde está na fila de espera da UTI . Revista Marketing. Editora Referência, 2011

http://www.vivaedeixeviver.org.br/valdir/colunas_pdf/2011/ComSusten_Outubro.pdf ( acessado 20.09.2014)

Cimino, Valdir; Eva e Pandora, as culpadas das desgraças do mundo?. Revista Marketing. Editora Referência, 2012

http://www.revistamarketing.com.br/materia.aspx?m=860 ( acessado 20.09.2014)

Cimino, Valdir; Inovar: política social e desenvolvimento na educação e saúde, Revista Marketing. Editora Referência, 2013

http://www.vivaedeixeviver.org.br/images/stories/imagens/noticias/Revista_mkt/Cimino.pdf ( acessado 20.09.2014)

GALEANO, Eduardo. De pernas pro ar: a escola do mundo ao avesso. Rio de Janeiro: LP\&M, 1999 